\title{
2. The power of visual political communication: pictorial politics through the lens of communication psychology
}

Darren G. Lilleker, Bournemouth University

\section{The power of the visual}

On 15 October 2008 presidential candidates Barack Obama and John McCain walked out on to the stage of the Hofstra University arena in New York for the third and final debate. A freeze frame of them taking their seats showed Obama as relaxed and self-assured; McCain lurched, tongue out, seeming to be scrabbling for this seat. The picture circulated widely on blogs, via Twitter and was picked up by a range of media outlets. The iconic image was framed as demonstrating the choice Americans faced (Burkeman, 2008). On 10 October 2016 the third debate took place at the University of Nevada in Las Vegas. Donald Trump's strategy was to undermine the credibility of his opponent Hillary Clinton, calling her a liar and a "nasty woman". An image of her speaking to the audience, with Trump stood behind her appearing to smugly dismiss her argument again gained a wide audience. Both images offered visual juxtapositions of the candidates, both were described as iconic, and may well have aided the decisions of some undecided voters. Whether highly sophisticated or unplanned, the visual in politics can convey as much meaning as any accompanying words and can equally elicit strong emotional responses. Both images could offer the impression of who would be the best leader of America and, ergo, the free world. Hence an image, if viewed as representing a synthesis of the choice to be made, can lead to impressions being formed that can prove decisive at the ballot box. .

The chapter argues that understanding the psychological importance of images is crucial for understanding much about $21^{\text {st }}$ Century politics and takes as its starting point the body of research that demonstrates the power of visual imagery to convey a meaning more powerful than can be expressed by words alone (Messaris, 1997). This body of work demonstrates visuals have unique power in political communication "because we believe our own eyes, but know well that people are manipulative, we tend to be verbally skeptical and visually gullible" (Joo et al, 2014: 217). While it is almost impossible to accurately measure the impact of any single image under real world conditions it is possible to suggest why visuals may have resonance and create affect. Therefore through a discussion of processes of socialization which create normative standards against which the real world is measured, then assessing the cognitive processes that occur at the point of exposure to visual political communication, this chapter deconstructs the power of the image from a psychological perspective, to explain why images resonate and manipulate peoples' beliefs and attitudes. The examples are largely drawn from research into political campaigns, but they are broadly applicable across the field of political communication as images are used to manipulate an audience to support a candidate, a policy, military intervention, the acceptance or rejection of refugees, to fight for environmental protection and to demonise an opponent. In every case the image must convey an idea that resonates with the learned values of their audience.

\section{Reading visuals, learning norms}

Learning to read often involves combining pictures and words to break monotony as well as to aid the learner understand the meaning of words and how they correspond to the real world (Samuels, 1970). Through the process of making heroes and villians instantly recognisable, education reading and 
entertainment permit children to map the world around them and develop perceptions of others based on their appearance and behaviour. The collection of cues from images is a core part of the process of socialization, whereby the norms and ideologies of a society become internalized. Socialization starts at birth and, depending on physical and social mobility, can take place across a life cycle as we learn and adapt to the society around us. Socialization processes provide both fixed and evolving schema, cognitive categorisations of information that define objects but more importantly political parties, leaders, candidates and policy stances. Schema allow people to judge the extent that real-world performances can be judged in terms of their fit to norms and expectations. Schema aid perceptions of what is normal or aberrant, and so form the building blocks on which political communication to be based. Schema can also lead to perceptions being manipulated through carefully crafted strategic political communication (Lilleker, 2014). Imagery can be used to portray ideal roles, behaviours and the norms of a given society, for example how a world leader should look or what makes a leader appear more authentic, honest, decisive or competent. Ufomata (1998) argues that if textbooks or advertisements show scientists or engineers as male, whereas females are portrayed as mothers or homeworkers, the aspirations of young females become restricted; they follow the path determined by social norms. Similarly, one might extrapolate that a female candidate for president is 'abnormal' and must prove herself to a far greater extent than any male rival. Zelizer (2004) argues media are crucial for propagating common perceptions through the strategic use of imagery controlling and manipulating societal norms . Political campaigns also seek to manipulate perceptions of what is right and wrong, encouraging their arguments to be internalized in the schema of their audiences. Visual representations of juxtapositions between right and wrong are argued to have specific resonance, due to their ability to capture an argument succinctly and ensure it is retained in memory.

At the most basic level schema permit us to recognize what is normal and what is not, linked to the animalistic instincts of fight or flight (Lilleker \& Pekalski, 2019). However they are also constructed around more fundamental rights and wrongs to aid arriving quickly at normative value judgements. Schema for political candidates, individuals or policies, particularly when linked to deeply held values, allow judgments to be make about how things are, how things ought to be, and who has the right character or policies to achieve what is required. Thus politicians are judged on whether they conform to the expectations embedded in a society's culture. Images are frequently used, particularly during election campaigns, to convey messages. The norms created through socialization are important as they act as controls upon human affect. Affect is the emotional response one has when being exposed to an image and assessing the information it holds compared to internalized norms and values. Images can been described as ideo-affective formations (Tomkins, 1962), composites of colors and content which as a whole and in parts elicit reactions ranging from enjoyment and excitement through to disgust, fear or shame. Images that break conventions can be surprising, shocking even repulsive, depending on how the context is read; familiarity can be comforting while also unremarkable. All these reactions are forms of affect resonance, where an emotional response is triggered that is internally meaningful to the receiver (Magai, 1999). Affect resonance is a powerful force underpinning attitude formation and providing the mobilization that results in behavior.

Political campaigns across the world use images to elicit affect. Candidates on the stump promising to bring 'change', reunify a nation, or make it great again attempt, through their words as well as the performative aspects when speaking, to engender feelings of hope and even excitement among those who believe their policies are correct, tenable and trust the candidate to enact them. Pictures or video showing known threats, warning of the danger to the economy or national security if a rival is elected, engender fear where the accusation is believable. Each image builds a schema around a candidature, the schema may form around strong associations with hope, unity, patriotism, economic stability,

Commented [DJ1]: Sentence doesn't quite make sense. Maybe split it up 
strength in foreign policy, protection against internal threats or a myriad other desires or threats citizens have internalized (Lilleker \& Pekalski, 2019). Through the learning processes that occur during an election contest a citizen might also internalize their support for a candidate due to the affect resonance of their campaign. Campaign visuals might make a candidate appear more 'authentic' or 'in touch', more accessible or likeable, or even more trustworthy; this effect was seen among the young UK voters who supported Jeremy Corbyn at the 2017 General Election (Lilleker \& Liefbroer, 2018). In this case extensive exposure to images of Corbyn with ordinary people, rappers, people from under-privileged and ethnic minority backgrounds built a schema associating him as being caring and in touch. Hence, in a fairly short term, Corbyn's performative acts socialized many young people to think of him as an honest and authentic individual based on their exposure to, mainly, visual campaign communication. As this is a group who on average possess lower levels of knowledge of and interest in electoral politics, as are many who vote for the more populist candidates (Inglehart \& Norris, 2016), it is useful to consider why visuals resonate particularly among those voters who are argued to be political cognitive misers.

\section{Visuals and the cognitive miser}

Affect resonate and occur almost instantaneously and cause an individual to engage emotionally with a piece of communication independent of their prior interest in the topic. While paying what Ellen (2010) calls continuous but partial attention to television news or scrolling through a feed on social media, an image can 'leap out', have an immediate emotional impact and lead to hot cognition, the 'wow that is important' moment. In an era of information overload, where the spaces humans most likely inhabit are filled with myriad images telling us something, it is likely much is ignored and little is given significant attention. But some images will stand out, be awarded complete attention, and then will be stored in memory to be retrieved subsequently when they are relevant. Communication that causes an immediate and strong emotional response, in particular eliciting desire or disgust, is most likely to capture attention.

Where there is an overabundance of information, perhaps coupled with low interest in the nature of the task (scrolling through a social media feed) rather than the end goal (keeping entertained on a commute), errors of judgment can occur due to certain pieces of information standing out while others fade to the background. The errors in assuming an argument is true humans can make is the subject of the next section, the point to make here is that when facing a range of information it is likely that content that is political will be processed summarily rather than being given extensive attention. The reason for this is that for the majority of citizens across the democratic world politics is a low involvement subject (Almond \& Verba, 2015), they lack interest in the minutiae of policy, the motivation to consider whether a promise is deliverable or an action will have the desired outcome. Popkin (1994) applied the concept of the cognitive miser to navigating the highly contested environments of US presidential campaigns. Popkin theorised that humans, in order to protect their mental processing resources, develop automatic processes and strategies to reduce cognitive effort as they navigate the social world. In the context of a US campaign the average voter simply wants to know the core premise each candidate offers and what is unique about their character and ability to be the best president (see also Kernell, 2006). Thus these citizens seek out the simplest way to find this data and develop a consistent perspective of what each candidate offers: they seek a coherent schema for each candidate to ensure they have minimal doubts when they cast their ballot. Hence, there is greater likelihood that politics will be understood more as a series of headlines which form a temporal narrative than being composed of detailed analysis. Hence research finds citizens have low and often skewed knowledge and base electoral decisions on partial information (Norris, 2011), the most accessible communication will likely have the greatest resonance and so impact on decision making. 
Popkin's theory, and subsequent research on voter knowledge and attitudes, suggests the average citizen can be easily manipulated. Rather than in-depth analysis of the promises made by each candidate, weighing evidence about their character or record, the more performative and visual aspects of campaign communication might be deemed easier vehicles from which to garner the required data. Juxtapositions of the youthful Barack Obama versus the frail-looking John McCain may have been one such image that had affect resonance in 2008; Obama eliciting positive emotions through his charismatic performance and an image that symbolized change. Perhaps similar notions of the ideal president were invoked by the image of Donald Trump towering over Hillary Clinton during the debates in the 2016 election contest. Such imagery, disseminated widely in media and online, become iconic images within an election contest, symbolizing the differences between candidates. These images flow through the media environment alongside candidate advertisements, news clips, unofficial campaign communication and user-generated memes each image adding information to the schema of the cognitive misers who pay continuous partial attention to election news. The correlation between attitudes, drawn from schema entries, and images circulated is proven; at least under experimental conditions. Research by Joo et al (2014) demonstrated a link between interpretations of images of Barack Obama during the 2012 presidential election contest and fluctuations in his approval ratings. The researchers recruited a panel to assess what characteristics Obama was demonstrating in a series of widely circulated images during the 2012 contest. The characteristics he was inferred to be communicating in the images were classified as being favorable or unfavorable. When the images circulated were interpreted as Obama looking angry or fearful, unfavorable characteristics, these predicted a dip in his ratings over the week following dissemination. In contrast when pictures that were widely disseminated were interpreted as showing Obama as competent, trustworthy or compassionate a subsequent higher rating was evident in opinion polls (Joo et al, 2014). While the study infers that those polled were exposed to these images, which could be an erroneous assertion, if their hypothesis is correct the research suggests such a simple difference between performative appearances can be used as an indicator of character and so lead to changes in approval ratings. Hence performance may well have a significant impact on election outcomes, the next section delves deeper into communication psychology to explore why this is the case.

\section{Thinking fast and looking for cues}

It would be wrong to assert that the miserly processing of political communication is a factor of the revolution in digital communication. However the trend in miserly cognition must be exacerbated within the fragmented, hypermedia environment in which the modern citizen lives in order that they protect themselves against information processing overload. Within this environment it is even more likely that the cognitive miser will seek out heuristics when navigating contested information environments, which constitute almost every political event, as well as relying on biases drawn from beliefs and simple value judgments: each of which suggest greater potential power and influence of the image.

The heuristics and bias approach to cognitive psychology suggests simplistic visuals and text are routinely used by humans to form impressions, impressions that can be at best incomplete and at worst false. These impressions can act as the foundation for schema, and inform attitudinal development that can limit the analysis or interrogation of information. Research in this field suggests the formation of impressions results from behaviors associated with the cognitive miser: solving problems while using minimal cognitive effort. Daniel Kahneman (2011), a pioneer of experiments in the field of automacy and decision making, proposed two cognitive processes: system one and system two thinking. System two involves serious consideration and reflection, the type of thinking that many 
assume to underpin political decision making but that is often found more in the context of high value purchases (Frederick, 2005). System one involves making snap decisions without serious reflection and likely allowing emotions to restrict analysis. This argument does not suggest emotions play no role in any form of decision making, particularly given the proven link between emotions and ethical choice making (Gaudine \& Thorne, 2001), rather that system one decision making can result purely from emotional, affect resonance, to a message which might be so strong they prohibit the opportunity for reflection. Cognitive psychologists have suggested that some people are inherently more likely to rely on system one thinking, hence the development of the cognitive reflection test (Toplak et al, 2014). The test, developed from the work of Kahneman and his collaborator Amos Tversky, is intended to test an individual's proclivity to devote serious cognitive effort to logic questions.

However, arguably any individual can find themselves in a state where they are unprepared, unable or unwilling to devote effortful thinking to any form of problem in which they invest lower importance or about which they have minimal knowledge (Tversky \& Kahneman, 1973). Under these conditions, the researchers argue, what matters is the availability or accessibility of data that offers a solution to the problem. Their argument highlights the importance of the schema, if one candidate stands out as having the most consistently positive associations in a schema they will be front of mind at the point of placing a ballot. Under these conditions Obama's youthful swagger, or Trump's powerful on stage presence, could have been important cues that they had the better credentials to be the US president.

Kahneman's dual system model of cognition neatly maps to the dual process elaboration likelihood model. System one thinking privileges a reliance on peripheral cues, the simple heuristics that imply an answer to the question posed. In developing the model, Petty and Cacioppo (1986) argue that people with low interest in a topic and/or low ability to comprehend any given piece of information will absorb basic impressions which will be stored in the memory and over time can combine with other impressions to form beliefs and attitudes. The peripheral processing dimension of the model informs us how visuals can lead to impressions being formed that in turn inform attitudes and behaviours. The collection of peripheral cues, headlines, news clips or memes, with visuals being particularly memorable and affective, if consistently giving a favorable or unfavorable impression, lead to the formation of a positive or negative attitude. The complexities around the claims regarding Hillary Clinton's honesty were difficult for many to untangle, including political analysts. The association with the words criminal and liar, reinforced by numerous amusing memes circulated on social media, may have made the claim more concrete and formed a negative attitude towards the Clinton candidacy (Dewberry, 2017) Once an attitude is formed there is a tendency to discount contrasting arguments as this leads to cognitive dissonance, the discomfort of having two contrasting sets of information and so an inconsistent schema. Hence, once an attitude is formed, voters will seek affirmation rather than information. The selective processing of information is referred to as confirmation bias, a theory which explains that once an attitude is formed people seek consistency and reinforcement (Oswald \& Grosjean, 2004). Simple images, whether positive or negative, if viewed frequently and the message is consistent, can be the building blocks of attitudes that will be protected and defended.

\section{Political performance as a visual cue}

What Petty and Cacioppo (1986) refer to as peripheral cues, and Kahneman (2011) as heuristics, are information shortcuts; summaries of the individual, their character and potential. They can be highly misleading, but they are not intrinsically inaccurate; the problem is that they open a route for manipulation to occur: if Clinton is believed to have lied once, it is possible everything she subsequently said was a lie. Humans use heuristics on a daily basis; they are important aids for navigating the world, supporting the identification of threats and shortcuts to gain satisfaction and 
safety. The learning of heuristics, such as the meaning of facial expressions, support many behavioral choices and, arguably, support the maintenance of the social norms on which trust and mutual understanding in any society rest. Learning that when a person smiles it signifies a welcome and is an indication of approachability is learned though safe interactions between a child and their parents, family, carers, teachers and peers; there is no risk to a young child for smiling inappropriately but they soon learn when it is appropriate and when it is not. They can also elicit meaning from another individual smiling, such as a candidate when delivering an argument. Through socialization processes we learn about more complex packages of meanings and learn to infer emotions from gestures, expressions, tone of voice and word usage. Most of these types of inferences are automatic. Inferences are used to develop a perception of the characteristics of another human, such as a candidate for president; again automatically and quickly. The problem is that forming such impressions, in a short time, through mediated information, does not allow a similar level of trial and error as a child has when learning when to smile. Hence the simplification of choices into reliance on simple heuristics that takes place during an election campaign has the risk of resulting in uninformed or misinformed decisions.

In defense of heuristics one might argue that those who watched the debate between presidential candidates John F. Kennedy and Richard Nixon formed a more accurate impression of Nixon than radio listeners. On radio Nixon proved to be a persuasive orator; the audience formed a mental picture of him as strong and presidential. However his visual appearance mediated his oratory among television viewers. Mainly due to a combination of illness and jetlag, Nixon appeared pale and sweaty and so was inferred to be less trustworthy than the tanned and composed Kennedy (Druckman, 2003). The Watergate scandal that would much later force Nixon from office perhaps indicated the heuristics drawn from his performance gave a reasonable impression of the man behind the rhetorical performance. The research has been subsequently discredited; however television, and the perceived importance of the performative aspects of the campaign, led to a much more personalized style of campaigning in the US (Kernell, 2006) and one where the visual performance is said to matter.

The above discussion sketches out the cognitive processes that make visual imagery powerful and how, in the context of political communication, visuals can be used to arrive at mental shortcuts to aid decision making. However, it is important to note that certain images have greater affect resonance than others. Goosens (1994) developed the Mental Imagery Processing model to explain the processual relationship between information processing, the contiguous emotional experience and subsequent cognitive appraisal. Drawing on enactive theories of perception, he hypothesized that greater affect resonance occurred under the conditions of 'seeing as doing'. Images that speak of action, where the audience can feel what it would be like to be part of the action being visualized, Goosens argued would have the greatest affect resonance. The reason for the heightened emotional affect is the stimulation of a range of emotions simultaneously as well as a physical reaction: goosebumps, spine chilling, sweaty palms, increased heart rate etc. Goosens thus proves the link between the intensity of the communication, the consequent intensity of consumers' feelings and the impact of the communication (Goosens, 2003). Images of a candidate with supporters at a rally might stimulate such emotions, similarly expressions of power may instil confidence in a potential leader, emotional displays can be read as signs of empathy or weakness depending on context; all are inferences based more on the performance than the substance. Hence the visual matters, and in an age where visuals can be constructed, manipulated and widely circulated, and where the strength of the emotional response precludes critical judgment, it could be that the most intense image will have the attitude changing resonance, not the one that accurately portrays reality. 


\section{A cognitive framework for understanding the power of the visual in a post-truth era}

Images can elicit a strong emotional and physical reaction. Images that create a buzz, are widely disseminated and viewed, can lead to a strong emotional reaction due to the affect resonance of the images among members of their audience and a perception is formed based on normative judgments. Many pieces of political communication attempt to gain virality through the intensity of the content, the intensity of the response relies solely on the interaction between the image and the nature and values of the person viewing that image. The veracity of the claim made, the meaning of the image, is less likely to be assessed rationally by the average cognitive miser who is exposed to the visual during their usual process of giving continuous partial attention to the communication environment and who is momentarily shocked into experiencing a strong emotional reaction. Many extremist groups, be they religious fundamentalists, neo-nazis or populists, appropriate imagery to engender strong emotional reactions and so further their cause. It may not be clear who created the image, or for what purpose, yet the image will be stored in a schema and may lead to the shaping of attitudes and behaviors. Large groups of dark-skinned adult male refugees are used to elicit fear of the unknown; individual children escaping war-torn countries are used to elicit empathy. Which image a person is exposed to most, and how they read each image in relation to their personal values and immediate concerns, can determine how they immediately respond cognitively and subsequently at the ballot box.

With the diminishing numbers sitting down to watch mainstream news bulletins and as more people are receiving news across multiple platforms (Newman, 2011) there is a blurring of what is official and unofficial, credible and warranting skepticism. Related to that phenomenon are shifts in motivations for going to certain news sources and consumer trust in news outlets (Lee, 2013). If one does not pay attention to the source, particularly when scrolling though material shared peer to peer on social media platforms, they can become exposed accidentally to all sorts of persuasive communication some of which comes under the classification of fake news (Allcott \& Gentzkow, 2017). It is thus a serious concern that much news shared on social media is what Chadwick (2018) and colleagues describe as democratically dysfunctional: news that is misinformation or disinformation. Much of this news will have minimal words, attractive images, and be designed to draw in audiences. The tabloids Chadwick et al accuse of poisoning the information well of social media operate on a clickbait model, producing words and images that are shareable and attract clicks which in turn earn them advertising revenue. Other clickbait sites operate, again using dramatic words and visuals to attract an audience (Lazauskas, Jacka \& Kažemėkaitè-Vitkauskienè, 2018). Alongside those who produce items that appear like news to attract clicks are political campaigners. Every campaign relies on visuals to convey their argument through the affordances of affect resonance through image construction. What we see, what resonates with us, and what we believe is a matter for the individual within this environment. Images are proven to be memorable and emotionally resonant, hence they are likely to impact attitudes and behaviours. This chapter sketches the main reasons why images might have a potent affect in politics to aid understanding of how those with lower interest may seek an easy answer to complex and contested political questions. It places the visual as one important component of the process of finding cognitive shortcuts, and while words, slogans and headlines equally provide shortcuts the visual may be the most memorable and resonant form of shortcut and it is certainly one that is used frequently within political communication.

\section{Conclusion}

Visual communication is a crucial part of human society. Humans navigate their way through the world using a forest of signs, seeking cues to aid an understanding of the environment. Most signs are processed automatically; occasionally due to surprise or shock humans pause to make meaning, but do 
we really understand the true meaning or the strategy behind the production of the message? This chapter has provided a guide to the basics of human cognition and why visuals, in a political context, aid the average citizens to locate the heuristics they seek, and form biases, in order to develop the political attitudes that inform behavior. In doing so the chapter sets the scene for subsequent empirical chapters which focus on specific case studies of how visuals can be powerful pieces of visual political rhetoric. In reading those chapters consider the cognitive processes that might make each form of visual political rhetoric so powerful. The contention here is that the majority of attitudes are likely to be formed through sporadic and partial interactions with the political information environment. Political schema are formed from exposure to simple pieces of political communication which collectively form an impression. Dramatic visual political rhetoric can elicit intense emotional responses, thus leaving an impression that is accessible and powerful. But visual communication can only be mere snapshots of information, they cannot tell the whole story, but they can capture attention and elicit affect resonance. As with any picture the most resonant may be able to tell 1000 words but 1000 words are not always sufficient to develop a coherent argument. Yet visual, partial and often strategic designed snapshots of the world, constructed and disseminated in order to exact political influence, can have significant power over decision making. The problem thus is that if the majority rely on heuristics, including visuals, in order to arrive at decisions, those decisions are likely to be insufficiently informed about the subsequent ramifications. When there is a reliance on visual heuristics the average citizen, a cognitive miser, can be manipulated into making political choices against their own interests.

\section{Bibliography}

Allcott, H., \& Gentzkow, M. (2017). Social media and fake news in the 2016 election. Journal of Economic Perspectives, 31(2), 211-36.

Almond, G. A., \& Verba, S. (2015). The civic culture: Political attitudes and democracy in five nations. Princeton University Press.

Burkeman, O. (2008) 'Americans: the choice is yours' The Guardian

https://www.theguardian.com/world/oliverburkemanblog/2008/oct/16/uselections2008-johnmccain1

Chadwick, A., Vaccari, C., \& O'Loughlin, B. (2018). Do tabloids poison the well of social media? Explaining democratically dysfunctional news sharing. New Media \& Society, 1461444818769689.

Dewberry, D. R. (2017) From Benghazi to Emails: two sides of the same scandal. In R. E. Denton (Ed) The 2016 US Presidential Campaign: Political Communication and Practice. (pp. 231-256). Palgrave.

Druckman, J. N., (2003). The power of television images: The first Kennedy-Nixon debate revisited. The Journal of Politics, 65(2), 559-571.

Ellen, R. (2010). "Continuous Partial Attention: Reconsidering the Role of Online Learning in the Age of Interruption". Educational Technology. 50 (4): 41-46.

Frederick, S. (2005). Cognitive reflection and decision making. Journal of Economic perspectives, 19(4), 25-42. 
Freedberg, D. (1989). The power of images: Studies in the history and theory of response. Chicago: University of Chicago Press.

Gaudine, A., \& Thorne, L., (2001). Emotion and ethical decision-making in organizations. Journal of Business Ethics, 31(2), 175-187.

Goossens, C. (1994). Enactive imagery: Information processing, emotional responses, and behavioral intentions. Journal of Mental Imagery, 18(3-4), 119-149.

Goossens, C. F. (2003). Visual persuasion: Mental imagery processing and emotional experiences. In Scott, L. M., Batra, R. (Eds.), Persuasive imagery: A consumer response perspective (pp. 129139). London, England: Laurence Erlbaum.

Inglehart, Ronald, and Pippa Norris. 2016. "Trump, Brexit, and the Rise of Populism: Economic Have-Nots and Cultural Backlash.” HKS Faculty Research Working Paper Series RWP16-026.

Joo, J., Li, W., Steen, F. F., \& Zhu, S. C. (2014). Visual persuasion: Inferring communicative intents of images. In Proceedings of the IEEE conference on computer vision and pattern recognition (pp. 216-223).

Kahneman, D., (2011). Thinking, fast and slow. London: Macmillan

Kelly, V. C. (1996), "Affect and the redefinition of intimacy", in Nathanson, D. L, Knowing feeling: Affect, script, and psychotherapy, New York: W.W. Norton, pp. 55-104

Kernell, S. (2006). Going public: New strategies of presidential leadership. CQ Press.

Lazauskas, D., Jacka, J., \& Kažemėkaitė-Vitkauskienè, I. (2018). Rage, giggles and fishing for clicks: A qualitative study on how clickbaiting affects perceived online news content quality. (http://www.diva-portal.org/smash/record.jsf?pid=diva2\%3A1215476\&dswid=8745)

Lee, A. M. (2013). News audiences revisited: Theorizing the link between audience motivations and news consumption. Journal of Broadcasting \& Electronic Media, 57(3), 300-317.

Lilleker, D. G. (2014). Political communication and cognition. Springer.

Lilleker, D. G. \& Liefbroer, M. (2018) 'Searching for something to believe in': Voter Uncertainty in a Post-Truth Environment, International Journal of Media \& Cultural Politics, forthcoming.

Lilleker, D. G., \& Pekalski, D. (2019). Schema Theory in Political Decision Making. In Redlawsk, D. P. (Ed.) Oxford Encyclopedia of Political Decision Making, Oxford University Press.

Magai, C. (1999). Affect, imagery, and attachment: Working models of interpersonal affect and the socialization of emotion. In J. Cassidy \& P. R. Shaver (Eds.), Handbook of attachment: Theory, research, and clinical applications (pp. 787-802). New York, NY, US: Guilford Press. 
Messaris, P. (1997). Visual persuasion: The role of images in advertising. Sage.

Newman, N. (2011). Mainstream media and the distribution of news in the age of social discovery. Reuters Institute for the Study of Journalism, University of Oxford.

Norris, P. (2011). Democratic deficit: Critical citizens revisited. Cambridge University Press.

Oswald M. E, Grosjean S., (2004) Confirmation Bias. In: Pohl Rüdiger F., (Ed.) Cognitive Illusions: A Handbook on Fallacies and Biases in Thinking, Judgement and Memory. Hove, UK: Psychology Press: 79-96.

Petty, R.E., and Cacioppo, J. (1983). Attitudes and persuasion: Classic and contemporary approaches. Dubuque, IA : William C. Brown.

Popkin, S. L. (1994). The reasoning voter: Communication and persuasion in presidential campaigns. University of Chicago Press.

Samuels, S. J. (1970). Effects of pictures on learning to read, comprehension and attitudes. Review of Educational Research, 40(3), 397-407.

Tomkins, S. (1962), Affect Imagery Consciousness: The Positive Affects, New York: Springer.

Toplak, M. E., West, R. F., \& Stanovich, K. E., (2014). Assessing miserly information processing: An expansion of the Cognitive Reflection Test. Thinking \& Reasoning, 20(2), 147-168.

Tversky, A., \& Kahneman, D. (1973). Availability: A heuristic for judging frequency and probability. Cognitive psychology, 5(2), 207-232.

Ufomata, T. (1998). Linguistic images, socialisation and gender in education. Africa Development/Afrique et Développement, 23(3/4), 61-75.

Verga, L., \& Kotz, S. A. (2013). How relevant is social interaction in second language learning?. Frontiers in human neuroscience, 7, 550.

Zelizer, B. (2004). When war is reduced to a photograph. In S. Allen \& B. Zelizer (Eds.), Reporting War: Journalism in Wartime (pp. 115-135). London: Routledge. 